\title{
UMA ESTRATÉGIA PARA ENSINAR O SISTEMA ÚNICO DE SAÚDE (SUS) NA ESCOLA PÚBLICA
}

\section{A STRATEGY TO TEACH THE UNIFIED HEALTH SYSTEM (SUS) IN PUBLIC SCHOOL}

\author{
Claudia Inês Aparecida DA LOZZO* \\ * Autor para contato: Mestre em Odontologia, Área de Concentração:Saúde Coletiva. Secre- \\ taria da Educação do Estado de São Paulo, Diretoria de Ensino Centro Sul. Rua Dom Antô- \\ nio Galvão Vila Gumercindo 04123040 - São Paulo, SP - Brasil. E-mail: claudiadalozzo@ \\ terra.com.br
}

Data de recebimento: 10/02/2014

Data da aprovação: 30/06/2014

\section{RESUMO}

Uma pesquisa exploratória, utilizando a metodologia quantitativa, foi aplicada em 441 alunos do Ensino Fundamental de uma escola pública, a Escola Estadual "Prof. a Mercedes Paz Bueno", do município de Bauru, SP, com a finalidade de verificar o nível de conhecimento dos alunos sobre o Sistema Único de Saúde (SUS), o funcionamento do sistema de saúde municipal, o conceito de saúde, e seus direitos em saúde. Após a aplicação de um programa educativo, 75,50\% dos alunos manifestaram que entenderam que devem recorrer ao Pronto-Socorro em casos de urgência e emergência para não sobrecarregar hospitais e Unidades Básicas de Saúde; 64,40\% informaram que utilizam os serviços oferecidos pela Unidade Básica de Saúde; $62,82 \%$ demonstraram que ainda possuem visão curativa, pois utilizam o SUS para algum tratamento ou diagnóstico; $58,95 \%$ manifestaram que entendem a saúde como um conceito de maior dimensão, ultrapassando o aspecto biológico, e 33,56\% revelaram possuir conhecimento ótimo sobre os programas de saúde oferecidos pelo município. Analisando os resultados obtidos pode-se concluir que o programa contribuiu para a compreensão significativa e construção do conhecimento, o que confirma o importante papel do professor na realização de projetos que articulem a teoria científica e a vivência dos participantes. Saúde é um tema transversal proposto nos Parâmetros Curriculares Nacionais, para ser desenvolvido de forma interdisciplinar e contínua no decorrer do ano letivo, visando contribuir para a formação crítica, consciente e participativa do jovem, como previsto nos princípios do SUS e na Lei de Diretrizes e Bases da Educação.

Palavras-chave: Educação. Saúde. Cidadania. Direitos do cidadão.

\begin{abstract}
A research was applied to 441 students of Basic Education at "Prof. Mercedes Paz Bueno" State School, using quantitative methodology, in order to verify the students level of knowledge about the "Health Unique System" (SUS), the operation of the city public health system, the health concept and their health rights. After the application of an educational program, 75,50\% understood that they should go to an Emergency Unit in emergency cases, so that they won't pack hospitals and Basic Health Units, 64,40\% use the services offered by Basic Health Units, $62,82 \%$ still go to "Health Unique System" (SUS) for treatment or diagnosis, $58,95 \%$ sees health as a bigger dimension of concept far over than the biological aspect and 33,56\% knows quite well about the health programs offered by the City System. Analyzing the results, the conclusion is that the program helped a significant comprehension and knowledge construction, that
\end{abstract}


confirms the important role of the teacher to develop projects that combines scientific theory and the participants life experiences. Health is a transversal theme given in the National Basic Education Laws to be developed in an interdisciplinary way and continues during the school year, leading to contribute to young people become critical, conscious and participative in the principles of "Health Unique System" (SUS) and in the Education Basic Law.

Keywords: Education. Health. Citizenship. Citizens rights.

\section{Introdução}

A educação e a saúde são duas áreas do conhecimento que devem ser concebidas de forma articulada, pois visam ao desenvolvimento pessoal e social dos indivíduos e à preservação da vida, o que justifica o fato de a escola ser um espaço apropriado para a vivência dos valores construídos em sociedade.

A saúde e a educação são parâmetros utilizados como indicadores de qualidade de vida de uma população, além de constituírem direitos assegurados a todos os brasileiros pela Constituição de 1988. O art. 196 da Constituição brasileira (BRASIL, 1988) trata a saúde como:

[...] direito de todos e dever do Estado, garantido mediante políticas sociais e econômicas que visem à redução do risco de doença e de outros agravos e acesso universal e igualitário às ações e serviços para a sua promoção, proteção e recuperação

No que se refere à educação, o direito universal também é garantido no art. 205 da mesma Constituição (BRASIL, 1988):

A educação, direito de todos e dever do Estado e da família, será promovida e incentivada com a colaboração da sociedade, visando ao pleno desenvolvimento da pessoa, seu preparo para o exercício da cidadania e sua qualificação para o trabalho.

O Ensino Fundamental é obrigatório, com duração de nove anos para todas as crianças de 6 a 14 anos, assegurando o seu ingresso e permanência na escola e a conclusão desse ensino a todo cidadão de acordo com a Constituição (Brasil, 1988), a Lei de Diretrizes e Bases da Educação Nacional - LDB (Brasil, 1996), e o Plano Nacional de Educação (Brasil, 2001), o qual, no item 2 da sua Introdução, ao falar dos Objetivos e Prioridades, explicita em que consiste a prioridade da alfabetização:

2. [...] A alfabetização dessa população é entendida no sentido amplo de domínio dos instrumentos básicos da cultura letrada, das operações matemáticas elemen- tares, da evolução histórica da sociedade humana, da diversidade do espaço físico e político mundial e da constituição da sociedade brasileira. Envolve, ainda, a formação do cidadão responsável e consciente de seus direitos e deveres. (BRASIL, 2001).

Quando se refere ao Ensino Básico no Brasil, o Ministério da Educação e Cultura (BRASIL, 2006) estabelece que:

O Ensino Fundamental e a Educação Infantil são duas etapas extremamente importantes para o desenvolvimento integral do ser humano. Os estímulos que uma criança recebe nos primeiros anos de vida definem seu sucesso escolar e seu desenvolvimento.

A escola oferece aos educandos a oportunidade de compartilhar saberes, organizar e estimular gradativamente, por meio de diferentes metodologias, a construção do seu próprio conhecimento, as impressões do mundo que os cerca, a conscientização a respeito da importância de uma vida saudável, o aprendizado sobre os direitos e deveres dos cidadãos, assim como proporciona a valorização das relações entre as pessoas e a aceitação das diversidades. Não só a comunicação se constitui no processo de comunicar, mas o próprio sujeito. (DE MARCO, 2012, p. 65).

$\mathrm{O}$ processo ensino-aprendizagem que ocorre nas diferentes áreas do conhecimento deve ser entendido como uma constante possibilidade de transformação, pois a todo instante estamos recebendo informações e escolhendo assimilá-las ou não. Atualmente, a prática educativa apoia-se na articulação da teoria com a vivência dos alunos, por meio de projetos estruturados a partir de valores que a sociedade julga necessário conservar ou transformar.

Algumas pesquisas comprovam que, por meio da realização de projetos, crianças, jovens e adultos conseguem um maior envolvimento no processo ensino-aprendizagem, fato que estimula o desenvolvimento de um cidadão crítico, participativo, multiplicador das informações recebidas e preparado para 
enfrentar os problemas e pensar soluções, pois faz parte do processo de formação educacional a vivência de situações nas quais uma postura autônoma é exigida. "Isso se ajusta à concepção de que o ato educativo é composto de um conhecimento (saber) e de ações resultantes desse conhecimento (fazer), devendo, o educando, ao aprender, incorporar o novo saber na sua ação diária”. (RODRIGUES, 2003, p. 24).

Os conceitos sistematizados induzem à conscientização reflexiva, que promove e aumenta a compreensão dos conceitos espontâneos que ocorrem no cotidiano e conduzem a uma reestruturação psicológica e real compreensão. Por conta disso "a aprendizagem se organiza de uma maneira mais completa no cérebro de uma pessoa quando solicita sua ação sobre o conhecimento e esta se manifesta mais organizada quando atravessa diferentes habilidades operatórias". (ANTUNES, 2007, p. 18).

A construção do conhecimento ocorre de forma individual, de acordo com o conhecimento prévio do aluno assim como da vontade de aprender. O processo de ensino-aprendizagem é conduzido pelo professor que, utilizando diferentes estratégias, como, por exemplo, as pesquisas, os jogos, os debates, e projetos interdisciplinares, proporcionam situações de aprendizagem que podem ser consideradas oportunidades para o desenvolvimento e a organização do pensamento. Assim, o aluno fica exposto a múltiplas perspectivas do ambiente, aprofunda seu entendimento por meio da interação com os outros e, em consequência, transforma o conhecimento prévio em novo. Como argumentam Abreu e Masetto (1990, p. 50): "[...] estratégias para aprendizagem constituem-se numa arte de decidir sobre um conjunto de disposição de modo a favorecer o alcance dos objetivos educacionais pelo aprendiz".

Pressupõe-se que o aprendizado se dá pela interação professor / estudante / conhecimento ao se estabelecer um diálogo entre as ideias prévias dos estudantes e a visão científica atual, com a mediação do professor, entendendo que o estudante reelabora sua percepção anterior de mundo ao entrar em contato com a visão trazida pelo conhecimento científico. (BRASIL. PCN - Ciências Naturais,1998).

Acreditando que a compreensão significativa do que está sendo ensinado depende da vontade do aluno em aprender, Machado (2004, p. 81) argumenta sobre a importância da realização de projetos para fa- cilitar o aprendizado:

Mais do que informar sobre os diferentes conteúdos, mais do que transmitir conhecimento, ao professor compete, precipuamente, despertar o interesse dos alunos, fazê-los querer, desejar, ter vontade, em outras palavras, estimular e semear projetos. São os projetos que nos mantêm vivos, que nos realizam como pessoa. Toda matéria, todo conhecimento é instrumento, é pretexto.

Dentro desta perspectiva, Rodrigues (2003, p. 23) afirma que o processo de assimilação dos alunos está relacionado ao estímulo dos professores que:

[...] devem trabalhar o educativo com a certeza de abordar uma ação cuja natureza se articule diretamente com a realidade vivida pelos educandos, pois essa articulação, aliada a uma dada concepção de mundo, direciona a ação dos homens.

Diferentes estudos confirmam que a compreensão somente é possível em momento evolutivo adequado, devendo haver uma adequação do ensino formal ao universo de conhecimento nas diferentes faixas etárias dos educandos. Portanto, ao preparar uma determinada aula, o professor deve estar consciente do estágio de desenvolvimento do educando, identificar a metodologia adequada de acordo com a faixa etária, como também o seu nível de compreensão, a fim de desenvolver corretamente suas competências e possibilitar a construção das estruturas mentais correspondentes. Tal função pode ser, entretanto, descaracterizada no processo educativo, que, ignorando o universo vivido pelo educando, se propõe a apenas realizar uma transferência de saberes dos educadores ou do material didático para os alunos. (RODRIGUES, 2003, p. 34).

Na mesma direção, Piletti e Piletti (1988, p. 254) afirmam que o aprendizado depende da articulação entre o conhecimento prévio do aluno com os novos conceitos apresentados durante o processo de construção do conhecimento:

Os conteúdos ensinados nas escolas precisam urgentemente deixar de ser estranhos, distantes, apresentados numa linguagem que os alunos não entendam, para possibilitar o conhecimento da realidade em que os alunos vivem e, a partir dela, levar ao conhecimento da realidade ampla, do país e do mundo.

No ambiente escolar, o educador é o profissional responsável pela condução do processo de aprendizagem dos conceitos, das atitudes e dos comportamentos, como também desempenha, junto ao educando, a construção da identidade, da 
autonomia e da liberdade. "O professor, através de sua prática pedagógica, pode ser comparado com um artesão que inventa soluções para os desafios impostos". (ANTUNES, 2007, p. 18). Pensando assim, a prática educativa deve ocorrer de maneira contínua, sensível às necessidades e às dificuldades dos educandos como também baseada nos conceitos que fundamentam a formação dos indivíduos. Como declaram Cyrino e Pereira (2004): “O aprendizado é um processo complexo; não acontece de forma linear, por acréscimo".

Visando à aprendizagem significativa, foram estabelecidos conceitos de fundamento baseados no Relatório da UNESCO da Comissão Internacional sobre Educação para o Século XXI. Esses conceitos são conhecidos como os quatro pilares da Educação: Aprender a conhecer, ou seja, desenvolver no aluno a vontade de aprender e querer saber mais, despertando a autonomia para gerenciar sua aprendizagem; Aprender a fazer, processo que articula a prática e a vivência aos seus conhecimentos teóricos; Aprender a viver com os outros, tipo de aprendizagem que desenvolve as atitudes e os valores nos educandos, a continuidade da produção cultural e práticas sociais, e da responsabilidade nos jovens indivíduos com sua vida e com a vida do que os cercam; e Aprender a ser, cujo aprendizado está relacionado ao desenvolvimento da sensibilidade, espiritualidade, autonomia e capacidade de agir de forma consciente. (UNESCO, 2010, p. 34).

Diante do exposto, pode-se concluir que, através da prática educativa responsável e consciente, o educador proporciona aos alunos o acesso ao conhecimento de forma plena, podendo desta maneira contribuir para uma formação integral. A participação em projetos interdisciplinares deve ser incentivada, pois possibilita a realização dos quatro pilares da educação, ou seja, a condução de um processo de ensino-aprendizagem significativo. "Nenhuma profissão, em nenhum tempo, dispõe da possibilidade presente ao magistério para modelar os seres que virão". (ANTUNES, 2007, p. 7).

\section{Educação, saúde e o trabalho}

Para realizar uma análise da construção histórica da educação, assim como da saúde e do trabalho no Brasil, devemos relembrar as constantes mudanças que ocorreram no decorrer das diferentes épocas e políticas públicas, influenciadas por movimentos socioeconômicos e culturais.

As ações educativas direcionadas para a saúde tiveram seu desenvolvimento no Brasil associado às campanhas de controle das grandes endemias de doenças infecciosas e parasitárias; campanhas que se caracterizaram, desde o início, por uma pedagogia higienista e uma prática de orientação vertical, voltadas para a manutenção da força de trabalho. (LOZZO, 2007, p. 34).

Essa parceria, saúde e educação, pode ser exemplificada por meio da análise das ações realizadas pelo Estado, através da Lei $n^{\circ} 378 / 1937$, que resolveu unir a Educação e a Saúde em um mesmo Ministério, cuja função era exercer atividades relativas à educação escolar, à educação extraescolar, à saúde pública e à assistência médico-social. Somente em 1953 aconteceu a divisão deste órgão, originando o Ministério da Educação e Cultura e o Ministério da Saúde.

Pensando em movimento socioeconômico e cultural, a década de 1960 é marcada por um momento capitalista que gerou mudanças na educação e no processo de trabalho, pois ambos "baseavam-se na produção em massa de mercadoria, que se estruturava a partir de uma produção mais homogeneizada e enormemente verticalizada". (ANTUNES, 1999, p. 36).

Em decorrência do momento histórico, a prática educativa daquele período foi marcada pelo ensino tradicional conteudista, no qual o professor era o único responsável pela transmissão de informações específicas de sua área do conhecimento. Seguia-se uma sequência rigorosa de conteúdos programáticos preestabelecidos e conceitos isolados nas diferentes áreas do conhecimento para posteriormente integrá-los. Além disso, para quantificar o conhecimento dos alunos, cabia aos professores elaborar e realizar provas, exames, sem a preocupação com o desempenho contínuo e habilidades desenvolvidas no decorrer do processo ensino-aprendizagem. Consequentemente, aos alunos cabia assimilar as informações de maneira mecânica, demonstrandoo conhecimento adquirido por meio de respostas fechadas e exatas. A fragmentação do saber e do fazer estava presente tanto no processo industrial quanto no educativo. Em virtude disso, na década de 1960, o processo educativo ocorria de maneira semelhante à produção de mercadorias 
em série nas indústrias, método denominado como fordismo. Com tal comparação, Antunes (1999, p. 37) declara que "esse padrão produtivo estruturou-se com base no trabalho parcelar e fragmentado, na decomposição das tarefas, que reduzia a ação operária a um conjunto repetitivo de atividades cuja somatória resultava no trabalho coletivo produtor de veículos". Na mesma sintonia, Gorz (2004, p. 38) comenta que:

[...] a rigidez era inerente ao modo de produção fordista: trabalho parcelado em longas cadeias de montagem concebidas para a produção em grande série de produtos padronizados; prazos extensos exigidos para produção e a estreita especialização da mão de obra; rígida hierarquia, quase militar, e enquadramento pletórico dos operários, cada um deles isolado em seu posto de trabalho, $[\ldots]$ rígida disciplina.

Ações direcionadas à educação em saúde continuam acontecendo na década de 1970. Foi criado para as escolas de $1 .^{\circ}$ grau do estado de São Paulo o Guia Curricular de Saúde, com o objetivo de estabelecer o que o aluno deveria saber com relação à saúde: crescimento e desenvolvimento, nutrição, higiene física, mental e social (higiene pessoal, saneamento do meio, lazer e trabalho e suas influências positivas e negativas na saúde, no comportamento social e prevenção de doenças), e agravos à saúde: conhecer medidas práticas e normas efetivas de prevenção de doenças que contribuirão para manutenção e promoção da saúde. (LOZZO, 2007, p. 36).

Na década de 1980 começa uma nova fase, marcada por mudanças no sistema educacional brasileiro com objetivo de melhorar e ampliar a educação da população por meio da criação de leis e parâmetros curriculares, estabelecendo assim uma referência curricular nacional. A mudança de paradigma na educação veio acompanhada de um vasto campo de investigação científica, com diversas correntes de pensamento, métodos e técnicas para entender a forma pela qual ocorre a aprendizagem em diferentes faixas etárias.

Naquele momento, novas ações educativas foram propostas com o objetivo de proporcionar aos alunos condições de continuamente colher e processar informações, de desenvolver sua comunicação, de avaliar situações e de tomar decisões que possibilitassem uma atuação positiva e crítica em seu meio social, isto é, superar as limitações do ensino passivo. Em um contexto no qual a escola deixa de ser a única detentora da informação e do conhecimento, a ins- tituição educacional começou a se preocupar com o desenvolvimento integral dos indivíduos. Os conteúdos conceituais, procedimentais e atitudinais começaram a propiciar aos alunos o desenvolvimento de uma melhor compreensão do mundo. Por meio dessas ações, o resultado desejado no decorrer do processo ensino-aprendizagem seria a formação de um estudante autônomo, crítico, atuante, consciente, ou seja, um jovem cidadão capaz de promover ações coletivas para tentar solucionar seus problemas e os da sua comunidade.

Em decorrência desta transformação, começa, na década de 1990, um movimento chamado "Educação para Todos", com a finalidade de proporcionar uma revisão e reflexão a respeito do papel do professor e da escola para o desenvolvimento do país, uma busca para a solução do problema educacional brasileiro. A partir deste momento, os professores são considerados a base do sistema educacional e também o fator determinante para a obtenção de um dos seis objetivos estabelecidos no "Fórum de Dacar sobre Educação para Todos": promover uma educação de qualidade (UNESCO, 2006b). Nesta direção, Abreu e Masetto (1990, p. 11) atribuem ao professor:

[...] o papel de despontar como sendo o de facilitador da aprendizagem de seus alunos. Seu papel não é só ensinar, mas ajudar o aluno a aprender; não é transmitir informação, mas criar condições para que o aluno adquira informações; não é fazer brilhantes preleções para divulgar a cultura, mas organizar estratégias para que o aluno conheça a cultura existente e crie cultura.

A UNESCO do Brasil, em sintonia com a Declaração Mundial de "Educação para Todos", participou da elaboração das diretrizes, das metas e das estratégias para os dez anos seguintes do Plano Nacional de Educação. No Brasil, a UNESCO realiza importantes Projetos de Cooperação Técnica com diversas instituições gestoras do Sistema Único de Saúde, desenvolvendo os seguintes eixos de ação: Educação Preventiva para o HIV/AIDS e DSTs; Educação Profissional; Educação em Saúde para a Atenção Básica; Pesquisa, Ciência e Tecnologia; e Monitoramento e Avaliação de Políticas Públicas (UNESCO, 2006a).Um dos projetos desenvolvidos pelo Ministério da Educação e Cultura, em parceria entre Ministério da Saúde, UNICEF e UNESCO, coordenado pela Secretaria de Educação Básica, Saúde e Prevenção nas Escolas, tem por objetivo o apoio às diferentes iniciativas que promovem a saúde 
e a prevenção nas escolas, com utilização diferentes estratégias, como, por exemplo, o incentivo à criação de uma política de educação preventiva nos sistemas de ensino de todo o país de forma articulada com o Sistema Único de Saúde (BRASIL, 2006).

A Secretaria da Educação do Estado de São Paulo (2006) destaca algumas diretrizes que orientam para o ensino-aprendizagem por meio do programa "A Saúde Começa na Escola", que articula as áreas da educação e da saúde no decorrer do ano letivo. Esse programa tem como finalidade:

Reconhecer que os conteúdos de saúde devem ser incluídos nas diferentes áreas curriculares; valorizar a promoção da saúde na escola para todos os que nela estudam e trabalham; entender que o desenvolvimento da autoestima e da autonomia pessoal é fundamental para a promoção da saúde; considerar a importância do desenvolvimento de estilo de vida saudável como opção viável e atraente para a prática de ações que promovam a saúde; oferecer formação continuada em Educação para a Saúde com participação de educadores que possam contribuir para a elaboração do projeto político-pedagógico de acordo com a realidade local e ou regional onde está inserida a escola; incentivar a adoção de um modelo de saúde que inclua a interação dos aspectos físicos, psíquicos, socioculturais e ambientais.

Seria relevante, portanto, o fomento da articulação do conhecimento à vivência tanto na escola quanto na comunidade por meio de um trabalho interdisciplinar, solidário na organização de uma escola que construa a educação em saúde. Segundo Cyrino e Pereira (2004, p. 780): “O processo de mudanças da educação traz inúmeros desafios, entre os quais romper com estruturas cristalizadas e modelos de ensino tradicional $[\ldots]$ "...

\section{Objetivos}

Esta pesquisa teve por objetivo geral identificar e avaliar o nível de conhecimento dos alunos do Ensino Fundamental sobre: a) conceito de saúde; b) funcionamento do sistema de saúde municipal; c) funcionamento do Sistema Único de Saúde (SUS). Como objetivo específico destaca-se a proposta de contribuir para a aquisição de informação, a conscientização e o acesso do jovem cidadão aos programas de atenção à saúde desenvolvidos pelo SUS. Além disso, ensinar sobre direitos e deveres em relação à saúde e despertar em nossos jovens cidadãos a consciência da necessidade de mudança de hábito com o objetivo de melhorar a qualidade de vida.

\section{Método}

Trata-se de uma pesquisa exploratória na qual foi utilizada uma análise de regressão que relaciona quantitativamente duas variáveis: o conhecimento do aluno do Ensino Fundamental e a introdução das informações para composição do conhecimento.

Foram abordados alunos do Ensino Fundamental em sala de aula, na unidade escolar Escola Estadual "Prof a . Mercedes Paz Bueno", do município de Bauru, estado de São Paulo. O trabalho, realizado com o consentimento dos pais ou responsáveis e da diretora da Escola e aprovação do Comitê de Ética em Pesquisa, teve como propósito a intervenção e a construção do conhecimento durante o processo ensino-aprendizagem. Para o desenvolvimento da pesquisa, diferentes técnicas pedagógicas foram aplicadas de acordo com as faixas etárias, as vivências e as condições para aquisição individual de conhecimento, várias estratégias de estímulo à curiosidade $\mathrm{e}$ à vontade de aprender. Antes da aplicação do questionário, os objetivos da pesquisa foram explicados aos alunos a fim de assegurar confiança e validade aos dados. Além disso, foram desenvolvidas técnicas pedagógicas diversificadas, como aula expositiva com o auxílio do multimídia, caça-palavras, cruzadinhas, leituras de histórias em quadrinhos (sobre direitos e deveres do cidadão) e 'descubra a frase secreta', visando o envolvimento, a assimilação e a construção do conhecimento. As atividades diversificadas foram realizadas em sala de aula, logo após a aula expositiva, na presença da pesquisadora e da professora responsável pela área de ciências, a fim de esclarecer quaisquer dúvidas dos alunos. Para avaliação do processo ensino-aprendizagem foi realizado um questionário sobre a saúde e o SUS, com 15 questões, uma aberta e 14 com várias alternativas, das quais cinco de múltiplas respostas e nove fechadas, que permitiam assinalar apenas uma alternativa.

Dos 552 alunos matriculados naquela unidade escolar, 441 alunos $(79,89 \%)$ participaram de todas as etapas do projeto, ou seja, pré-teste com aplicação de questionário, aula expositiva, atividades diversificadas e pós-teste. Portanto, por meio desta amostra aleatória simples sem reposição, num estudo de caso (unidade escolar), os seguintes parâmetros estatísticos foram atingidos: $99 \%$ de confiabilidade, margem de erro de $3,2 \%$ e probabilidade do fenômeno se verificar de $50 \%$. 
Ao final das atividades propostas, os alunos receberam uma cartilha do Programa de Cidadania desenvolvida em 2003, na Universidade do Sagrado Coração, com o objetivo de reforçar o conteúdo desenvolvido a respeito da rede de serviços da Secretaria Municipal de Saúde. Para que não houvesse dúvidas quanto aos resultados obtidos na pesquisa, foram excluídos os questionários dos alunos que não estavam presentes em todos os momentos do programa educativo.

A aplicação do pós-teste aconteceu em maio, dois meses depois da primeira etapa do projeto, com retorno às mesmas séries e reaplicação do mesmo questionário para identificar possível assimilação a respeito do tema desenvolvido e, consequentemente, construção do conhecimento. A fim de se extraírem as conclusões, foi utilizada estatística descritiva através de tabelas e gráficos com valores absolutos e relativos, de acordo com os objetivos propostos na pesquisa.

\section{Resultados}

Esse estudo foi realizado na Escola Estadual "Profa. Mercedes Paz Bueno", localizada na região central de Bauru, que recebe alunos vindos de 60 bairros do município. Participaram de todas as etapas da pesquisa (pré-teste, aula expositiva, atividades diversificadas e pós-teste) 441 alunos do Ensino Fundamental, destes: 109 alunos do $6^{\circ}$ Ano A-B-C-D; 137 do $7^{\circ}$ Ano A-B-C-D-E; 95 alunos do $8^{\circ}$ Ano A-B-C-D; e 100 alunos do $9^{\circ}$ Ano A-B-C-D. A faixa etária desse grupo de alunos variou entre 10 e 21 anos, com predominância do grupo entre 11 e 14 anos de idade. Para análise dos dados coletados, após a aplicação do programa educativo, foi utilizada estatística descritiva por meio de tabelas e gráficos com valores absolutos e relativos para elaboração das conclusões, de acordo com os objetivos propostos na pesquisa.

Fonte: Os autores.
Os resultados obtidos estão demonstrados nos cinco gráficos a seguir, acompanhados dos respectivos comentários.

$\mathrm{O}$ número de alunos que assinalaram a opção “(4) Todas as alternativas estão corretas" aumentou de $46,94 \%$ para $58,95 \%$. Por meio desse resultado, pode-se observar que os alunos começaram a entender Saúde como um conceito de maior dimensão, ultrapassando a dimensão biológica. Relacionaram saúde a outros fatores como, por exemplo, alimentação, moradia, saneamento básico, meio ambiente, trabalho, renda, educação, transporte, lazer e acesso aos bens e serviços essenciais, e não somente à ausência de doença. Resultado positivo que vai ao encontro do que determina a Lei ${ }^{\circ} 8.080 / 90$, no art. $3^{\circ}$ :

A saúde tem como fatores determinantes e condicionantes, entre outros, a alimentação, a moradia, o saneamento básico, o meio ambiente, o trabalho, a renda, a educação, o transporte, o lazer e o acesso aos bens e serviços essenciais; os níveis de saúde da população expressam a organização social e econômica do país.

Parágrafo único. Dizem respeito também à saúde às ações que, por força do disposto no artigo anterior, se destinam a garantir às pessoas e à coletividade condições de bem-estar físico, mental e social.

A visão da saúde como ausência de doença demonstrada na alternativa "(1) Não ter dor, febre, doença." diminuiu de 7,08\% para 4,08\%; assim como diminuiu de $29,25 \%$ para $17,91 \%$ a porcentagem de alunos que responderam a alternativa "(2) Ter higiene

Gráfico 1 - Identificação do conceito individual de saúde

\section{Conceito Individual de Saúde}

- Percentual de respostas Pré-teste $\quad$ Percentual de respostas Pós-teste

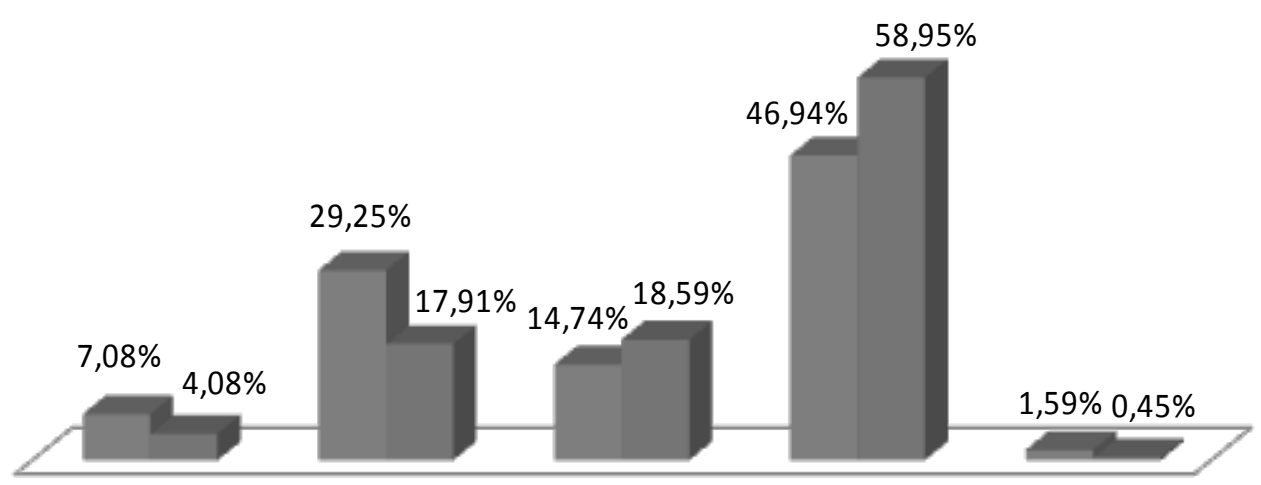


e se alimentar bem. " Esta alternativa revela a cultura higienista, estabelecida na década de 1920, devido ao grande desenvolvimento industrial e ao processo de urbanização e crescimento das cidades, que ainda está presente nos cuidados com a saúde. Naquele período, uma das funções da saúde pública era a higienização e o disciplinamento das cidades e de seus habitantes, como prevenção de doenças e promoção da saúde através das práticas de higiene e da educação sanitária. Esse pensamento surgiu em 1924 quando foi criado, no Rio de Janeiro, o $1^{\circ}$ Pelotão de Saúde em uma escola estadual. Em 1925, com a finalidade de "promover a formação da consciência sanitária da população, dos serviços de higiene do Estado e dos serviços de profilaxia geral e específica", Horácio de Paula Souza criou a Inspetoria de Educação Sanitária e os Centros de Saúde do Estado de São Paulo, cuja responsabilidade era a divulgação de noções de higiene para os alunos das escolas primárias estaduais. Foi instalado, no Instituto de Higiene, o primeiro curso para professores primários com o objetivo de formar educadores sanitários para desenvolver as ações sanitárias junto à comunidade. Além disso, a Fundação Serviço Especial de Saúde Pública (SESP) começou a preparar as professoras da rede pública como agentes educacionais da saúde. (LOZZO, 2007, p. 35).

A porcentagem dos alunos que assinalaram a alternativa “(3) Estar bem com você mesmo”, aumentou de $14,74 \%$, no pré-teste, para $18,59 \%$, no pós-teste. Esse resultado demonstra que a pessoa, para ter saúde, deve estar em equilíbrio com corpo e mente, como também com as pessoas e com o meio que a cerca. Felizmente, a maioria dos jovens já possui noção do que deve ser feito para preservar e manter a sua saúde, pois somente $1,59 \%$, diminuindo para $0,45 \%$, dos alunos assinalaram a alternativa "Não sei."

As diferentes respostas obtidas na questão aberta "Como você utiliza os serviços do SUS?” foram analisadas e classificadas dentro de quatro categorias: "Diagnóstico e tratamento; Não sei; Não utiliza; Promoção da saúde e prevenção." O gráfico 2 apresenta o resultado.

Fonte: Os autores.
A visão curativa da população ficou evidente nesta questão aberta, pois aumentou de $51,70 \%$, no pré-teste, para $62,82 \%$, no pós-teste, a porcentagem de alunos que declararam utilizar o SUS quando necessitam de consulta médica e odontológica; sentem-se doentes ou estão com febre, alergia, bronquite; necessitam fazer exames ou cirurgia; precisam de remédios; assim como atendimento de urgência/emergência como dor, ferimento com faca e com arma, mordida de cão, cólica renal, fratura, acidente, choque etc. Essas respostas foram classificadas na categoria "Diagnóstico $e$ tratamento". Após as ações educativas diversificadas, houve diminuição de $39,23 \%$ para $18,14 \%$ do número de alunos que responderam "Não utilizo", como também de $4,99 \%$ para $4,31 \%$ a porcentagem dos que responderam "Não sei". Aumentou de 4,08\% para $14,74 \%$ a porcentagem dos alunos que relacionaram ações do SUS a "Promoção/Prevenção". Respostas como vacina, pré-natal, controle da pressão arterial, saneamento, controle da água, do alimento e dos remédios, vigilância sanitária e epidemiológica foram classificadas nessa categoria. Esse aumento pode ser atribuído ao aprendizado a respeito das ações desenvolvidas pelo SUS, que muitas vezes não são mencionadas pela população. Dados como esses, obtidos em pesquisa com educandos que refletem em suas respostas a opinião de seus responsáveis, corroboram o que já foi evidenciado durante a Conferência Nacional de Saúde: "O Ministério da Saúde entende que existem dificuldades para utilizar

Gráfico 2 - Demonstração em porcentagem a forma pela qual os alunos utilizam os serviços do SUS

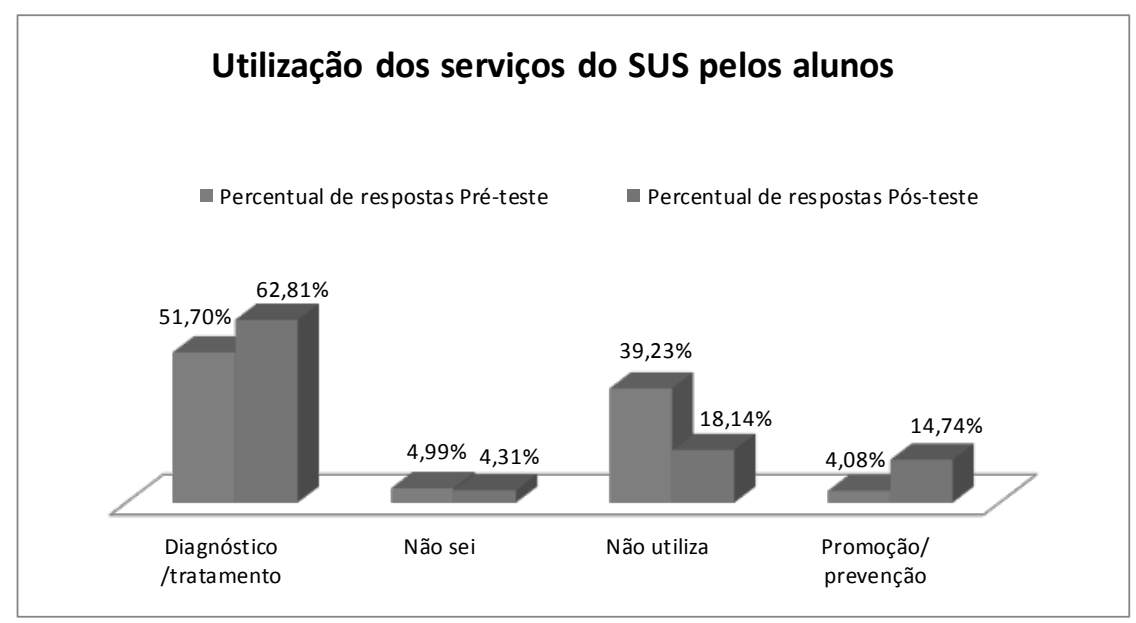


o SUS, por desconhecimento de seus programas e ações por parte da população". (BRASIL, 2001, p. 31). É importante ressaltar que a utilização do SUS para reabilitação não foi mencionada entre os 441 alunos que responderam esta questão.

A falta de informação contínua e a necessidade de conscientização da população sobre a função e os serviços oferecidos nas Unidade Básica de Saúde (UBS) ficou demonstrada no gráfico 3.

Gráfico 3 - Número de alunos que utilizam os serviços oferecidos na Unidade Básica de Saúde (UBS)

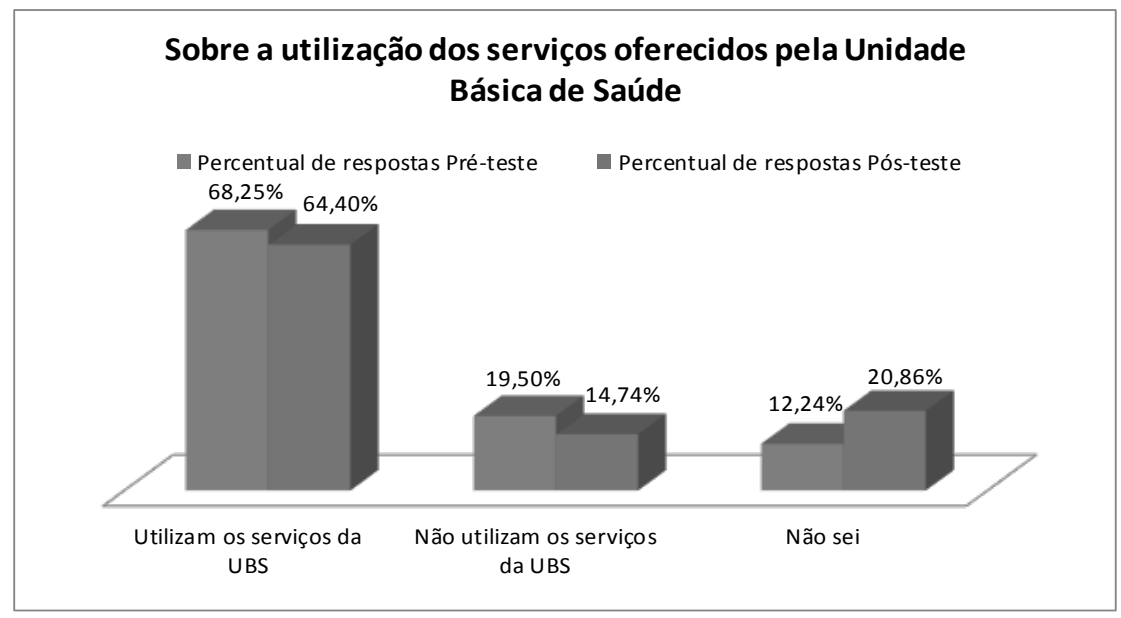

Fonte: Os autores.

Em relação à pergunta "Você já utilizou o Posto de Saúde (UBS) de sua cidade?", 68,25\%, no pré-teste, diminuindo para $64,40 \%$, no pós-teste, responderam que "Sim". Esse resultado sugere que, mesmo após ações diversificadas, muitos não relacionaram a assistência básica, como, por exemplo, consultas e vacinação, às UBS. Os alunos não devem reconhecer a UBS como porta de entrada para o atendimento em saúde; em decorrência, devem procurar o pronto-socorro ou hospital, sobrecarregando o sistema de saúde preparado para atender casos de emergência.

Entre o pré-teste e o pós-teste houve o aumento de 12,24\% para $20,86 \%$ dos alunos que responderam a alternativa "Não sei". Esta dúvida se já foram ou não atendidos em um Posto de Saúde pode ser justificada

Fonte: Os autores. pela faixa etária em que se encontram, pois são seus responsáveis que os encaminham para atendimento em saúde quando necessitam, e podem ter procurado atendimento em uma clínica ou até hospital ligado ao seu plano de saúde privado. Entretanto, diminuiu de $19,50 \%$ para $14,74 \%$ a porcentagem dos alunos que afirmaram "Não ter utilizado a UBS", pois perceberam que em alguns momentos de sua vida como, por exemplo, vacinação, receberam o atendimento em um posto de saúde. Os programas de atenção primária oferecidos pelo SUS nas UBS deveriam ser mais divulgados pelo governo, nas escolas e na mídia, para que todos tivessem a informação e aprendessem como utilizar.

Com a finalidade de avaliar o nível de conhecimento dos alunos a respeito dos diferentes programas de saúde oferecidos pelo município, foi perguntado quais os programas que eles conheciam: consultas médicas, consultas de enfermagem, consultas com nutricionistas, consulta com psicólogos, vacinação, curativos, pré-natal, prevenção do câncer, tratamento odontológico, tratamento da diabetes, tratamento da hipertensão arterial, controle das DSTs, planejamento familiar, entrega de remédio, inalação. Por se tratar de uma questão com várias alternativas, o maior número de alternativas assinaladas seria considerado resultado ótimo.

Gráfico 4-Nível de conhecimento dos alunos a respeito dos diferentes programas de saúde oferecidos pelo município.

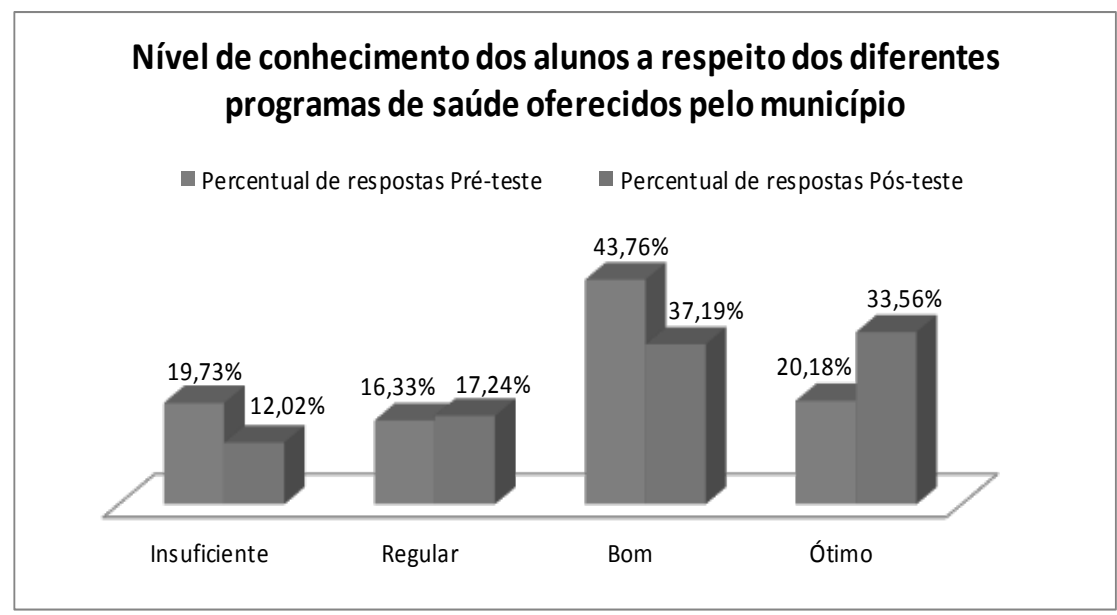


Os alunos demonstraram, após o programa educativo, ter conhecimento sobre o tipo de atendimento que seu município oferece. Aumentou de $20,18 \%$ para $33,56 \%$ a porcentagem dos alunos que demonstravam conhecimento "Ótimo"; de 16,33\% para $17,24 \%$ dos alunos com conhecimento "Regular". Diminuiu de $19,73 \%$ para $12,02 \%$ a porcentagem dos alunos que, no primeiro momento, não conheciam os programas de saúde e assinalaram de 1 a 4 alternativas, demonstrando conhecimento "Insuficiente", assim como de $43,76 \%$ para $37,19 \%$ os que assinalaram de 8 a 12 programas demonstrando conhecimento "Bom". Diante da análise das informações fornecidas no gráfico 4 , pode-se concluir que seria necessário intensificar a divulgação e o esclarecimento a respeito dos programas de saúde oferecidos, projetos e financiamento da saúde, além de deixar mais claro o que significa cada um desses programas. Dessa maneira, o atendimento em saúde oferecido pelo SUS poderia atingir um maior número de pessoas, como também o acesso seria facilitado.

Para avaliar se os alunos têm conhecimento a respeito dos locais que prestam atendimento de urgência/emergência, foi perguntado para onde deveria ser encaminhada uma pessoa atropelada. Felizmente demonstaram por meio de suas respostas ter conhecimento sobre o tipo de atendimento que devem recorrer por estar preparado para um rápido atendimento em casos de urgência e emergência. Os dados estão demonstrados no gráfico 5 .

Gráfico 5 - Nível de conhecimento dos alunos a respeito do local a que deve ser encaminhada uma pessoa que precisa de um atendimento de urgência e emergência

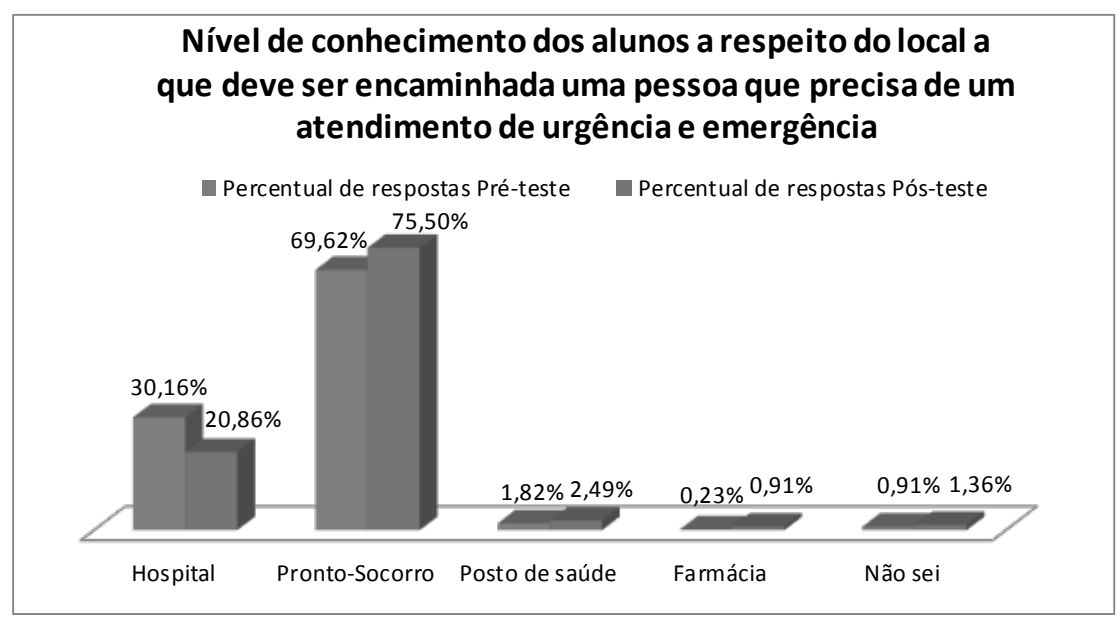

Fonte: Os autores.
Comparando os dados coletados entre o pré e pós-teste, houve uma redução de $30,16 \%$ para $20,86 \%$ do número de alunos que responderam procurar o "Hospital", e o aumento de $69,62 \%$ para $75,50 \%$ dos alunos que responderam que deveriam encaminhar uma pessoa atropelada para um "Pronto-Socorro". Apenas uma pequena parte dos alunos assinalaram no pré-teste e pós-teste as alternativas "Posto de Saúde!", "Farmácia” ou "Não sei”.

\section{Discussão}

Os resultados verificados no pós-teste, obtidos após a aplicação das atividades educativas, reiteram a importância de se trabalhar o conceito de saúde de forma ampliada como tema transversal de maneira interdisciplinar, valorizando a articulação entre as disciplinas que integram as áreas: Linguagens e códigos e suas tecnologias; Ciências humanas e suas tecnologias; Ciências da natureza; Matemática e suas tecnologias. A troca de experiência entre professores e a partilha de saberes consolidam espaços de formação mútua, nos quais cada professor é chamado a desempenhar, simultaneamente, o papel de condutor do aprendizado assim como também pode aprender com alunos e demais professores. $\mathrm{O}$ diálogo entre professores é fundamental para consolidar saberes emergentes da prática profissional. (NÓVOA, 1992).

A escola e a família têm como objetivo comum preparar pessoas para a vida. Faz parte do processo ensino-aprendizagem oferecer condições para o jovem cidadão criar sua identidade com autonomia e independência, além de aprender a compreender, conviver e respeitar as diversidades na forma de ser, pensar, agir das pessoas que o cercam. O desenvolvimento do individuo depende da capacidade de construção do próprio conhecimento por meio da articulação das vivências com os saberes produzidos pela humanidade. Durante o processo de formação, as pessoas sofrem constante influência do seu núcleo familiar e social, dos conceitos desenvolvidos durante todo processo de ensino que ocorre em uma escola. Ocorre, também, não só a interferência da cultura regional e 
global divulgada pelos meios de comunicação, que exercem grande influência na opinião da população, mas ainda a intervenção positiva e negativa causada pela internet na formação de opinião política e econômica.

No decorrer do processo educativo, os conceitos sistematizados induzem à conscientização e à consciência reflexiva, que promove e aumenta a compreensão dos conceitos espontâneos do dia a dia, levando a uma reestruturação psicológica nos modos de compreensão do conhecimento. A imaturidade abre espaço para a construção e a transmissão da cultura, de modo que, na formação do ser, temos, ao lado da evolução condicionada pela herança genética, a evolução proporcionada pela herança cultural. (DE MARCO, 2012, p. 69).

A escola deve oferecer condições para o aluno construir seu conhecimento, desenvolver suas habilidades e incorporar no seu dia a dia o conhecimento construído. Além de tudo isso, uma instituição educacional precisa contribuir para que o aluno aprenda a pensar e a expressar seus pensamentos e não apenas ser um sujeito apto a receber conhecimentos já cristalizados ao longo do tempo. Agindo dessa forma, a escola estará preparando o jovem protagonista para a vida.

Quanto à importância da articulação entre a vivência do aluno e o que é ensinado em sala de aula, Orso (2000, p. 2) argumenta que:

Os alunos têm muitas informações sobre educação e saúde. Mas, de modo geral, não conseguem aplicar em suas vidas, pois normalmente há um distanciamento muito grande entre a realidade, o conhecimento e as condições de colocá-los em prática no contexto em que vivem.

Considerando a faixa etária dos alunos envolvidos nesse programa educativo, os jovens adolescentes refletem em seus relatos, suas vivências assim como os comentários realizados por seus responsáveis.

Analisando os comentários dos alunos quanto ao atendimento em saúde em seu município, as reclamações ocorrem devido à necessidade de ter que esperar tempo demais para ser atendido, como também pela falta de qualidade e respeito no atendimento. Após a aplicação do programa e análise dos dados coletados, ficou evidente que falta para a população maior esclarecimento a respeito da forma como está organizado o atendimento em saúde em sua cidade, pois a informação facilita o acesso e o atendimento. Se os usuários buscam atendimento em saúde em um hospital quando deveriam recorrer ao Pronto-Socorro, ou mesmo à UBS, ou, então, quando desconhecem a UBS como porta de entrada para atendimento, sobrecarregam o sistema, desencadeando as reclamações e dificuldade no atendimento, conforme está previsto na Constituição e nos princípios e diretrizes do SUS.

A escola, sendo responsável pela formação do jovem cidadão, possibilita a efetiva participação social como está previsto nas diretrizes do SUS. Toda ação que começa de forma individual pode se tornar social e política.

Entendendo a importância da formação de indivíduos capazes de se responsabilizar pela própria saúde, além de se preocupar com a saúde dos demais indivíduos de sua comunidade, como também construir o conceito de saúde de forma ampliada, o conteúdo está presente no currículo do estado de São Paulo, da $5^{\mathrm{a}}$ à $8^{\mathrm{a}}$ série do Ensino Fundamental - Ciclo II, através do eixo temático 'Ser Humano e Saúde', como também nos Parâmetros Curriculares Nacionais, sendo desenvolvido de forma transversal no decorrer do ano letivo. Dessa forma, os jovens cidadãos estarão aptos à participação racional e responsável do controle da saúde assim como da educação, que são patrimônios do povo brasileiro.

A educação deve ser entendida como prática da cidadania que possibilita a mobilização da comunidade. Toda mudança requer participação e conhecimento e a escola pode proporcionar esse conhecimento e consequente transformação dos muitos sujeitos sociais, considerando que projetos individuais com o passar do tempo se tornam projetos coletivos.

Projetos como este devem ocorrer de forma contínua e sistematizada ao longo do ano letivo com o objetivo de oferecer condições para a formação de sujeitos críticos, participativos e transformadores, pois só através do conhecimento a sociedade poderá participar e exercer seus direitos e deveres como está previsto na Constituição brasileira.

Diante desta constatação, faz-se necessário intensificar a realização de projetos interdisciplinares que articulem as áreas de educação e saúde, buscando a constante informação e formação dos educandos. 


\section{Conclusão}

Essa pesquisa buscou, através de ações diversificadas, a articulação entre as áreas da educação e da saúde com os objetivos de identificar o nível de conhecimento dos alunos do Ensino Fundamental a respeito do conceito individual de saúde. Além disso, informar e contribuir para a conscientização sobre a importância do conhecimento das instituições de atendimento e dos programas públicos de saúde, assim como identificar de que maneira a comunidade utiliza os serviços oferecidos pelo SUS.

De acordo com as informações coletadas após programa educativo, pode-se concluir que 58,95\% dos alunos entendem o conceito de saúde de forma ampliada, o que confirma a importância da união entre as áreas da saúde e da educação. Através de projetos e de metodologias diversificadas, durante o processo ensino-aprendizagem, os alunos não só conseguiram construir conhecimentos integrando conceitos apresentados pelo professor em sala de aula às experiências vividas em seu cotidiano, mas também desenvolver suas habilidades e competências como, por exemplo: ler, escrever, selecionar, organizar, relacionar, interpretar dados e informações apresentadas de diferentes formas com o objetivo de tomar decisões e enfrentar situações-problema; tornar-se responsável por uma ação e suas consequências; construir argumentação consistente e recorrer aos conhecimentos desenvolvidos na escola nas várias áreas do conhecimento para elaborar propostas de intervenção solidária na realidade, respeitando os valores humanos $\mathrm{e}$ considerando a diversidade sociocultural.

Os alunos transmitiram, em suas respostas, conceitos atitudinais, visto que $62,82 \%$ responderam que utilizam o SUS para tratamento ou diagnóstico, e ainda, pelo desconhecimento de suas outras funções, como está previsto no art. 200 da Constituição. A análise só confirmou a falta de informações sobre as atribuições do SUS e sua importância na manutenção da saúde individual e coletiva do Brasil. Por isso, evidencia-se a necessidade do desenvolvimento de atividades contínuas e sistematizadas com temas relacionados à educação em saúde na rede de ensino, com o objetivo de contribuir com a formação do jovem cidadão, além de desconstruir a visão curativa da população e proporcionar a visão preventiva.

Dos 441 alunos que participaram da pesquisa, $64,40 \%$ responderam que utilizam os serviços ofere- cidos na Unidade Básica de Saúde, 33,56\% possuem conhecimento ótimo quanto ao nível de conhecimento a respeito dos diferentes programas de saúde oferecidos nos municípios pelo SUS nas Unidades Básicas de Saúde. A visão da comunidade sobre o SUS fica evidente nas respostas dos alunos, pois, na faixa etária em que se encontram, expressam a opinião de seus responsáveis. Para que o atendimento atinja um maior número de pessoas, a população deveria conhecer a organização do atendimento do sistema de saúde em sua cidade, uma vez que a informação facilita o acesso e o atendimento como está previsto nas diretrizes do SUS. Além disso, seria necessário intensificar, na mídia e nas escolas, as informações sobre os programas de atenção à saúde, com o objetivo de maior envolvimento e aprendizado dos alunos multiplicadores das informações que recebem. Ao aprender, as crianças, os jovens e os adultos incorporam o novo saber na sua ação diária, muitas vezes mudando valores, costumes e, consequentemente, mudanças de hábito da população.

Ressaltando a importância do professor e da ação educativa, após o programa educativo, 75,50\% dos alunos entenderam que devem recorrer ao Pronto-Socorro só em casos de urgência e deixar de buscar, de forma errada, atendimento nas Unidades Básicas onde encontram atendimento emergencial primário, a fim de não sobrecarregar hospitais. Estas instituições estão preparadas para o atendimento de situações de maior complexidade, com isso o sistema hospitalar ou os funcionários não ficariam sobrecarregados, o que proporcionaria melhor atendimento, diminuição das longas filas de espera e, consequentemente, das reclamações. Ou seja, o atendimento aconteceria de forma integral, com qualidade e respeito a todos os cidadãos.

Com o objetivo de proporcionar um aprendizado significativo com abordagem dos conteúdos conceituais, procedimentais, atitudinais, os valores humanos, também deverão propiciar aos alunos situações vinculadas não só ao contexto real, mas que também colaborem com a construção de um conhecimento novo a partir do conhecimento prévio. Desta maneira os educandos conseguiriam rever seus conceitos, testar novas ideias, enfrentar e propor soluções para os problemas, visto que conhecimento é algo que se constrói! 
Se a intenção for a formação do sujeito com atuação positiva e crítica em seu meio social, capaz de superar as limitações do ensino passivo, assim como a formação de um aluno cidadão autônomo, crítico, consciente e capaz de uma ação coletiva que resulte na melhoria da qualidade, inclusive, de seus familiares; então a prática educativa deve proporcionar subsídios para o aprendizado e também incentivar e valorizar o exercício da cidadania e a participação social.

Ainda que seja função do educador estimular, "educar", conduzir a transformação do jovem cidadão, protagonista de uma nova geração, que aspire às mudanças, e que necessita tornar-se mais participativo e responsável por ações, decisões e controle, cabe aos seus familiares ou responsáveis participar dessa transformação que começa de maneira individual e logo se torna coletiva. Para isso, seria preciso que a sociedade reconhecesse o exercício de seus direitos e deveres constitucionais, evitando o comportamento passivo e dependente, de quem aguarda mudanças sem se envolver, sem se sentir parte do Estado. Pensando a educação como ato contínuo, complexo, que não ocorre de maneira linear, e nem sempre no momento desejado pelo educador, podemos citar uma afirmação de Machado (2004, p. 11): "Sem ilusões, não se é - ou se permanece - professor".

Diante do exposto, espera-se que esta pesquisa alcance a proposta inicial, ou seja, a contribuição para a formação integral do jovem cidadão, além de despertar a consciência de seus direitos e deveres em saúde. Com análise do processo de construção dos alunos envolvidos, durante a realização desse estudo, podemos concluir que projetos interdisciplinares são essenciais para a construção significativa do conhecimento dos sujeitos envolvidos no processo de ensino-aprendizagem. "Ensinar não é transferir conhecimento, mas criar as possibilidades para a sua própria produção ou a sua construção". (FREIRE, 1996, p. 21).

\section{Referências}

ABREU, Maria Célia de; MASETTO, Marcos Tarciso. O professor universitário em aula. 8. ed. São Paulo: Editora MG Editores Associados, 1990.

ANTUNES, Celso. Como transformar informação em conhecimento. Petrópolis, RJ: Vozes, 2007.

BRASIL. Constituição (1988). Constituição da República Federativa do Brasil. Brasília, DF: Senado, 1988.
Disponível em: <https://www.planalto.gov.br/cc ivil_03/ Constituicao/Constitui\%C3\%A7ao.htm>. Acesso em: 10 fev. 2006.

BRASIL. Ministério da Educação. Lei de Diretrizes e Bases da Educação Nacional. Brasília: MEC, 1996. 21p.

BRASIL, Ministério da Educação e Desportos. Secretaria da Educação Fundamental. Parâmetros Curriculares Nacionais. Brasília: MEC, 1998.138p.

BRASIL. Ministério da Educação. Plano Nacional de Educação. Brasília, 2001. Disponível em: <http:// portal.mec.gov.br/seb/index.php?option=content $\&$ task=view\&id $=715 \&$ Itemid $=71>$. Acesso em: 25 out. 2006.

BRASIL. Ministério da Saúde. Pacto pela Saúde. Brasília, 2006. Disponível em: <http://portal.saude.gov.br/portal/ saude/area.cfm?id_area=1021>. Acesso em: 1 out. 2006.

CONFERÊNCIA Nacional de Saúde (11. 2000; Brasília). Efetivando o SUS. Acesso, Qualidade e Humanização na Atenção à Saúde com Controle Social: Relatório Final/ Ministério de Saúde - Brasília, 2001.

CONFERÊNCIA Nacional dos Bispos do Brasil. Setor Pastoral Social. A Prática da cidadania como educação política. Petrópolis, RJ: Vozes, 1996.

CYRINO, Eliana G.; PEREIRA, Maria Lúcia T. Trabalhando com estratégias de ensino-aprendizado por descoberta na área da saúde: a problematização e a aprendizagem baseada em problemas. Cad. Saúde Pública. Rio de Janeiro, v. 20, n. 3, p. 780-788, 2004.

DELORS. Jacques (coord.). Educação: um tesouro a descobrir. Relatório para a Unesco da Comissão Internacional sobre Educação para o século XXI. São Paulo: Cortez; Brasília: MEC/Unesco, 1980. cap. 4, p. 89-102. Disponível em:http://unesdoc.unesco.org/ images/0010/001095/109590por.pdf.

DE MARCO, Mário Alfredo et al. Psicologia médica: abordagem integral do processo saúde-doença. Porto Alegre: Artmed, 2012. 383p.

FREIRE, Paulo. Pedagogia da autonomia. Saberes necessários à prática educativa. São Paulo: Paz e Terra, 1996. $165 \mathrm{p}$.

GORZ, André. O imaterial. Conhecimento, valor e capital. Tradução de Celso Azzan Júnior. São Paulo: Annablume, 2004.

LOZZO, Claudia Inês Aparecida Da. Formação educacional para os direitos do cidadão em saúde: uma contribuição. 2007, 120f. Dissertação (Mestrado em Odontologia - Saúde Coletiva) - Universidade do Sagrado Coração. Bauru, SP, 2007.

MACHADO, Nilson José. Educação: projetos e valores. 5. ed. São Paulo: Escrituras, 2004. (Coleção Ensaios Transversais). 
NÓVOA, Antônio. Os professores e sua formação. Lisboa: Dom Quixote, 1992.

ORSO, Paulino Jose. Educação e saúde. A interdisciplinaridade como desafio. Rev. on-line Bibl. Prof. Joel Martins, Campinas-SP, v. 2, n. 1, out. 2000. 5p.

PIAGET, Jean. O juízo moral na criança. Tradução de Elzon Lenardon. São Paulo: Summus Editorial, 1994.

PILETTI, Claudino; PILETTI Nelson. Filosofia e História da Educação. 6. ed. São Paulo: Ática, 1988. 264p.

RODRIGUES, Neidson. Da mistificação da escola à escola necessária.11. ed. São Paulo: Cortez, 2003. 97p.

SÃO PAULO. Secretaria da Educação do Estado de São Paulo. Proposta Curricular. 2008.

UNESCO - Organização das Nações Unidas para a Educação, a Ciência e a Cultura. Disponível em: <http://www.unesco.org. br/areas/educacao/areastema ticas/edsaude/index_html/mostra_documento>. Acesso em: 20 out. 2006.

UNESCO - Organização das Nações Unidas para a Educação, a Ciência e a Cultura. Disponível em: <http://www.unesco.org. br/areas/educacao/efa2006/professoresqualificados/mostra_documento>. Acesso em: 20 out. 2006.

\section{ANEXOS}

\section{ATIVIDADES DIVERSIFICADAS}

1 - História em quadrinhos (sobre direitos e deveres do cidadão)

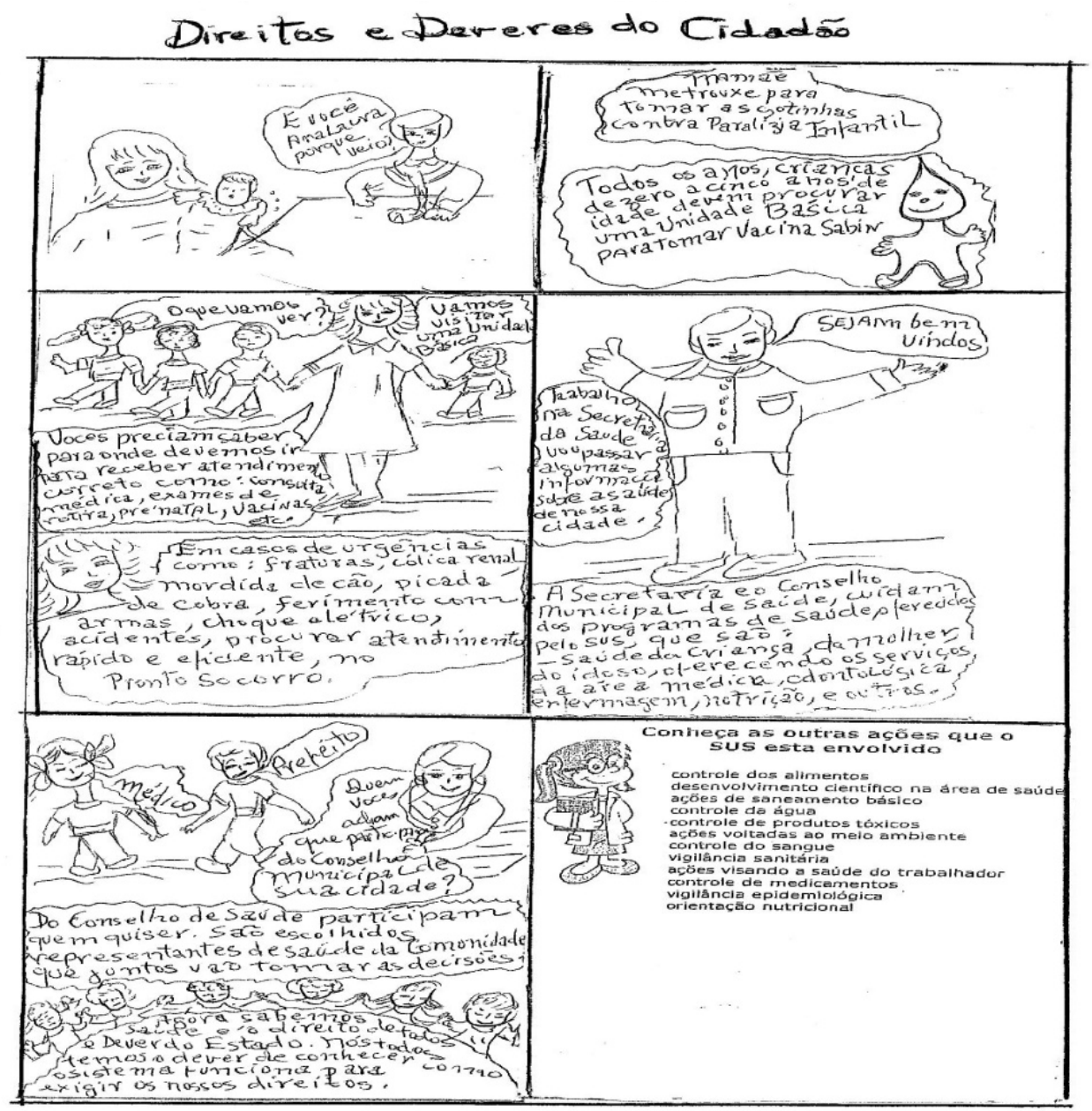


Dimeitos e Deveres do Cidadao

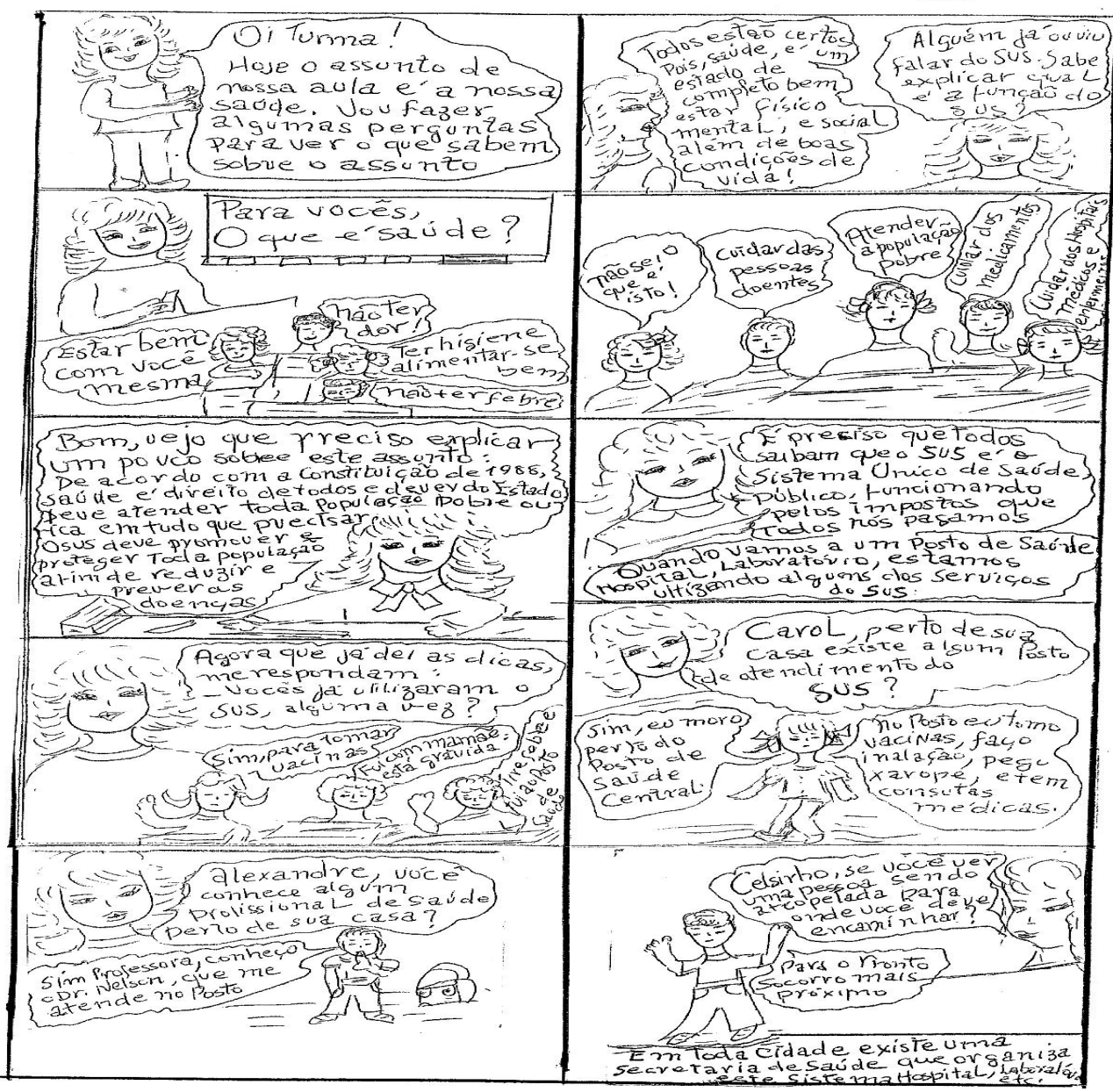

2- Complete as cruzadinhas

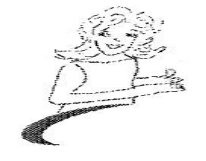

comprete as cruzadirimas:

a) Assistência primária destinada à saúde das criansas.

b) Local onde os casos graves devem encaminhados.

c) Em cada município, o Sistema unico de Saúde se divide

em unidades básicas, pronto socorro e ............

d) Um dos servisos prestados pela uBs é a .......médica e odontológica.

e) As UBS réalizam ......... primária em saúde.

f) Todo município possui um......... para decídir sobre os programas oferecidos pelo sus

g) Pessoas que sofrem .........5âo levadas para o pronto socorro.

h) Sistema único de Saúde é o mesmo que..........

i) A assistência básica á saúde da crianga, da muiher e do adulto acontece nas .......

j) Toda mulher quando fica grávida deve fazer parte do programa...... realizado nas UBS.

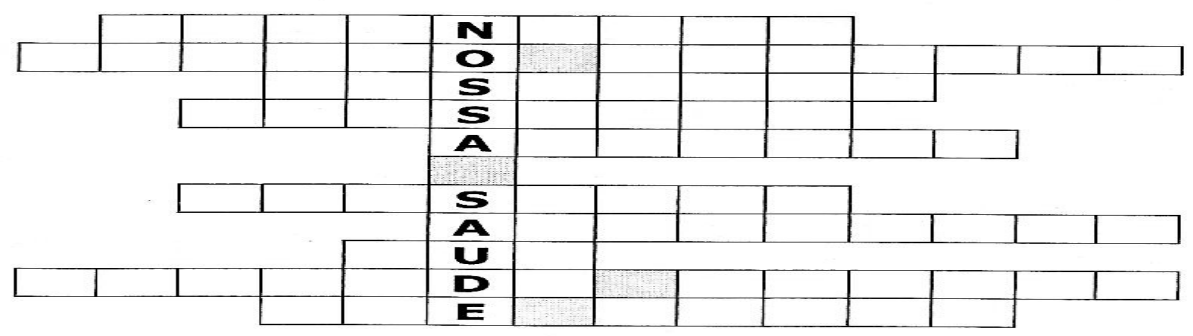

Publ. UEPG Ci. Biol. Saúde, Ponta Grossa, v.20, n.2, p. 149-164, jul./dez. 2014 Disponível em <http://www.revistas2.uepg.br/index.php/biologica> 
3- Descubra a frase secreta

2

C

Descubra a frase secreta:

\begin{tabular}{|c|c|c|c|c|c|c|c|c|c|c|c|c|c|c|c|c|c|c|c|c|c|c|c|}
\hline A & B & C & D & E & F & G & H & I & J & K & L & M & N & O & P & Q & R & S & T & U & V & X & Z \\
\hline 1 & 2 & 3 & 4 & 5 & 6 & 7 & 8 & 9 & 10 & 11 & 12 & 13 & 14 & 15 & 16 & 17 & 18 & 19 & 20 & 21 & 22 & 23 & 24 \\
\hline
\end{tabular}

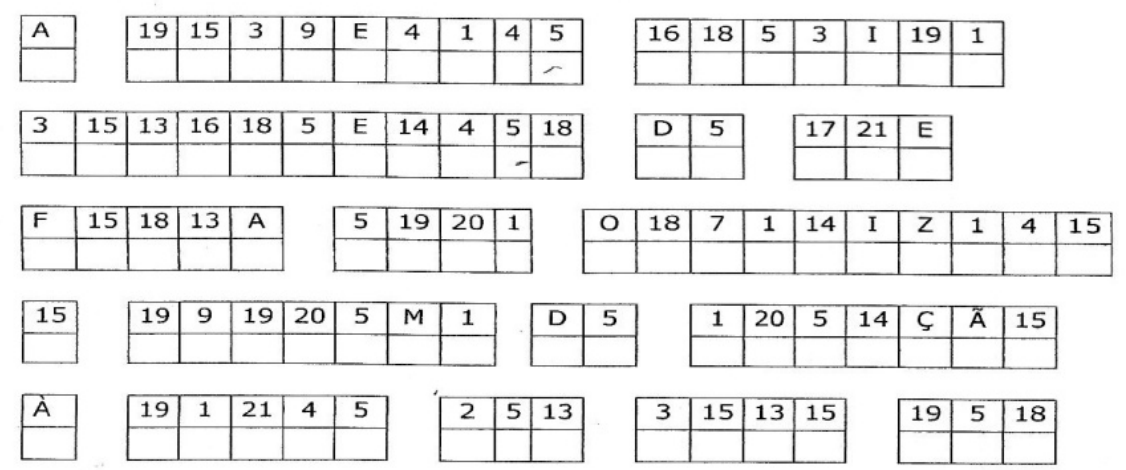

\begin{tabular}{|l|l|l|l|l|l|l|l|l|l|l|l|l|l|}
\hline 15 & 18 & 9 & 5 & 14 & 20 & 1 & 4 & 15 \\
\hline & & & & & & & & \\
\hline
\end{tabular} \mid \begin{tabular}{|l|l|l|l|l|l|}
19 & 15 & 2 & 18 & 5 \\
\hline & & & & \\
\hline
\end{tabular}

\begin{tabular}{|l|l|l|l|l|l|}
\hline$E$ & 1 & $C$ & 9 & 12 \\
\hline & & & & \\
\hline
\end{tabular}$\quad$\begin{tabular}{|l|l|l|l|l|l|l|}
\hline 1 & 3 & 5 & 19 & 19 & 15 \\
\hline & & & & & \\
\hline
\end{tabular}$\quad$\begin{tabular}{|l|l|l|l|l|l|l|}
\hline 17 & 21 & 1 & 14 & 4 & 15 \\
\hline & & & & & & \\
\hline
\end{tabular}

\begin{tabular}{|l|l|l|l|l|l|l|l|l|l|l|l|l|}
\hline 21 & 19 & 21 & 1 & 18 & 9 & 15 \\
\hline & & & & & & \\
\hline
\end{tabular}$\quad$\begin{tabular}{|l|l|l|l|l|}
\hline 2 & 19 & 20 & 1 \\
\hline & & & \\
\hline & & 13 \\
\hline
\end{tabular}

\begin{tabular}{|l|l|l|l|l|l|l|l|l|}
\hline 9 & 14 & 6 & 15 & 18 & 13 & 1 & D & 15 \\
\hline & & & & & & & & \\
\hline
\end{tabular}

\section{4- Caça palavras}

Caca palavras

\begin{tabular}{|c|c|c|c|c|c|c|c|c|c|c|c|c|c|c|}
\hline A & $\mathbf{L}$ & $M$ & 0 & $F$ & A & D & A & $s$ & u & $\mathbf{I}$ & $\mathbf{P}$ & $T$ & $M$ & $\mathbf{v}$ \\
\hline$s$ & A & $\boldsymbol{U}$ & D & $\mathbf{E}$ & D & 0 & $\mathbf{E}$ & $s$ & C & 0 & L & A & $\mathbf{R}$ & $\mathbf{x}$ \\
\hline $\mathbf{H}$ & $\mathbf{I}$ & $\mathbf{A}$ & $\mathbf{T}$ & $x$ & $\mathbf{I}$ & $\boldsymbol{T}$ & $x$ & $r$ & $\mathbf{N}$ & 0 & A & 0 & $\mathbf{T}$ & $\mathbf{G}$ \\
\hline $\mathbf{P}$ & $\mathbf{L}$ & I & $s$ & 0 & $\mathbf{Q}$ & A & w & $\mathbf{E}$ & $\mathbf{R}$ & $\mathbf{T}$ & $\mathbf{N}$ & $s$ & $\mathbf{K}$ & $\mathbf{I}$ \\
\hline $\mathbf{R}$ & $M$ & I & A & v & A & $\mathbf{L}$ & $\mathbf{I}$ & A & $\mathbf{N}$ & $C$ & $\mathbf{E}$ & $\mathbf{I}$ & $\mathbf{v}$ & L \\
\hline E & $\mathbf{P}$ & $\mathbf{I}$ & $\mathbf{u}$ & $v$ & A & $\mathbf{I}$ & J & A & C & A & $\mathbf{J}$ & 5 & $P$ & $A$ \\
\hline $\mathbf{v}$ & $\mathbf{I}$ & 0 & D & 0 & $\mathbf{N}$ & A & $\mathbf{r}$ & $\mathbf{L}$ & 0 & $\mathbf{N}$ & A & A & $\mathbf{I}$ & $\mathbf{N}$ \\
\hline E & $\mathbf{P}$ & $\mathbf{R}$ & $\mathbf{E}$ & - & $\mathbf{N}$ & A & $\mathbf{T}$ & A & L & $\mathbf{I}$ & $M$ & $\mathbf{U}$ & A & C \\
\hline $\mathbf{N}$ & $G$ & 0 & $M$ & A & $\mathbf{E}$ & $\mathbf{P}$ & 0 & $\mathbf{R}$ & $\mathbf{T}$ & A & $\mathbf{E}$ & D & A & $\mathbf{I}$ \\
\hline$C$ & 0 & A & $\mathbf{E}$ & $\mathbf{P}$ & $u$ & $\mathbf{L}$ & A & $\mathbf{R}$ & U & D & $\mathbf{N}$ & $\mathbf{E}$ & $M$ & A \\
\hline A & $\mathbf{N}$ & $\mathbf{T}$ & $\mathbf{N}$ & $\mathbf{I}$ & $\mathbf{B}$ & $\mathbf{A}$ & $\mathbf{T}$ & A & $\mathbf{T}$ & A & $\mathbf{T}$ & D & 0 & $\mathbf{N}$ \\
\hline 0 & $T$ & $s$ & $T$ & L & $\mathbf{T}$ & $\mathbf{N}$ & 0 & $s$ & $\mathbf{I}$ & $M$ & 0 & 0 & $\mathbf{R}$ & U \\
\hline D & D & $\mathbf{I}$ & A & $\mathbf{B}$ & $\mathbf{E}$ & $\mathbf{T}$ & $\mathbf{E}$ & $s$ & $H$ & $z$ & $\boldsymbol{F}$ & $\mathbf{T}$ & $\mathbf{E}$ & $\boldsymbol{T}$ \\
\hline 0 & 0 & $v$ & $\mathbf{L}$ & $\mathbf{T}$ & 0 & A & $\mathbf{G}$ & $\mathbf{T}$ & $\mathbf{P}$ & $\mathbf{E}$ & A & $\mathbf{R}$ & $\mathbf{P}$ & $\mathbf{R}$ \\
\hline C & $\mathbf{E}$ & C & $H$ & $\mathbf{E}$ & $\mathbf{G}$ & $\mathbf{T}$ & $\mathbf{A}$ & $\mathbf{T}$ & u & $\mathbf{E}$ & $M$ & A & $\mathbf{T}$ & $\mathbf{I}$ \\
\hline A & $\mathbf{R}$ & Q & $s$ & 0 & A & B & $C$ & $P$ & 0 & $\mathbf{P}$ & $\mathbf{I}$ & $\mathbf{B}$ & $\mathbf{w}$ & c \\
\hline $\mathbf{N}$ & $\mathbf{T}$ & D & w & $\mathbf{N}$ & $\mathbf{T}$ & $\mathbf{I}$ & $\mathbf{L}$ & $\mathbf{H}$ & $\mathbf{G}$ & $\mathbf{I}$ & L & A & $\mathbf{I}$ & $\mathbf{I}$ \\
\hline C & A & $s$ & A & $Q$ & $H$ & L & $\mathbf{I}$ & $\mathbf{N}$ & $\mathbf{H}$ & A & $\mathbf{I}$ & $\mathbf{L}$ & $\mathbf{P}$ & 0 \\
\hline $\mathbf{E}$ & 0 & D & 0 & $\mathbf{N}$ & $\mathbf{T}$ & 0 & L & 0 & $\mathbf{G}$ & $\mathbf{I}$ & A & $H$ & B & $\mathbf{N}$ \\
\hline $\mathbf{R}$ & A & $\mathbf{R}$ & $H$ & $\mathbf{I}$ & $P$ & $\mathbf{E}$ & $\mathbf{R}$ & $\mathbf{T}$ & $\mathbf{E}$ & $\mathbf{N}$ & $\mathbf{R}$ & A & 0 & A \\
\hline $\mathbf{I}$ & 0 & $\mathbf{I}$ & $\mathbf{P}$ & $\mathbf{T}$ & $Y$ & w & $z$ & $\mathbf{I}$ & L & $\mathbf{u}$ & $\mathbf{T}$ & D & C & $\mathbf{L}$ \\
\hline 0 & $\mathbf{I}$ & $\mathbf{P}$ & $E$ & A & L & $\mathbf{N}$ & $\mathbf{I}$ & $Q$ & U & $\mathbf{E}$ & $\mathbf{I}$ & 0 & $\mathbf{I}$ & $F$ \\
\hline $\mathbf{H}$ & 0 & $s$ & $\mathbf{P}$ & $\mathbf{I}$ & $\mathbf{T}$ & A & L & o & $\mathbf{J}$ & $\mathbf{A}$ & $\mathbf{E}$ & $\mathbf{R}$ & 0 & $\mathbf{B}$ \\
\hline
\end{tabular}

Prevençáo do câncer - Saúde Mental - Diabetes

Odontologia - Hospital - Saúde do Trabalhador - Pré-Natal Saúde do Escolar - Vigilancia Nutricional - Planejamento Familiar 